\title{
Lytinis gyvenimas: galvos skausmo trigeris ar malšintojas?
}

\author{
M. Jokubaitis* \\ K. Ryliškienè $* *$ \\ *Vilniaus universitetas, \\ Medicinos fakultetas \\ **Vilniaus universitetas, \\ Neurologijos centras
}

\begin{abstract}
Santrauka. Lytinės veiklos sukeltas galvos skausmas (LVS) yra pirminis galvos skausmas, sukeliamas lytinės veiklos ar atsirandantis jos metu. Literatūroje nurodomas LVS paplitimas siekia apie 1-1,6\% . Nepaisant to, spejjama, kad ligos dažnis gali būti kur kas didesnis dèl pacientų vengimo išsakyti skundus, susijusius su lytine veikla. LVS pasižymi dideliu komorbidiškumu su kitais pirminiais galvos skausmais. Ligos gydymas susideda iš skausmo priepuolių malšinimo ir priepuolių prevencijos. Šiame straipsnyje apžvelgiama LVS epidemiologija, skausmo charakteristikos, diagnostiniai kriterijai, diferencinè diagnostika ir gydymas. Aptariamas pirminio galvos skausmo ir moterų lytinės disfunkcijos komorbidiškumas bei lytinių santykių poveikis pirminiam galvos skausmui.
\end{abstract}

Raktažodžiai: lytinės veiklos sukeltas galvos skausmas, skausmo charakteristikos, diagnostika, gydymas, moterų lytinè disfunkcija.

\section{IVADAS}

Lytinė veikla yra gerai žinoma pirminio lytinės veiklos sukelto galvos skausmo (LVS) priežastis [1], tačiau šio skausmo aprašymai medicininèje literatūroje yra negausūs, o medikamentinès skausmo ir jo prevencijos galimybès yra rekomendacinio pobūdžio. Dar mažiau turima duomenų apie migrenos ir įtampos tipo galvos skausmo poveikį moterų lytinei funkcijai. Lytinè disfunkcija (angl. sexual dysfunction, LD) - terminas, apibūdinantis lytinès funkcijos sutrikimus, apimančius lytinị potraukị, susijaudinimą ir pasitenkinimą [2]. Nors lytinès funkcijos sutrikimai prastina gyvenimo kokybę [3], skundai, susiję su LD, dažnai neišsakomi dèl kultūrinio visuomenès spaudimo [4]. Negana to, migrena sergančios moterys yra stigmatizuojamos, joms siūlomas moksliniais duomenimis nepagrịstas galvos skausmo malšinimas lytiniais santy-

\footnotetext{
Adresas:

Mantas Jokubaitis

Vilniaus universiteto Medicinos fakultetas

M. K. Čiurlionio g. 21, LT-03101 Vilnius

El. paštas mantas.jokubaitis1@gmail.com
}

kiais [5]. Apie lytinès veiklos sukeltą galvos skausmą ir LD vengia kalbèti ne tik pacientai, bet ir gydytojai [6]. Dèl minètų priežasčių yra svarbus aktyvus gydytojo vaidmuo, klausiant apie skausmą lytinių santykių metu ir dèl dažnos migrenos ar ittampos tipo skausmo patiriamus lytinès funkcijos sutrikimus. Šiame straipsnyje apžvelgiama LVS epidemiologija, skausmo charakteristikos, diagnostiniai kriterijai, diferencinè diagnostika ir gydymas. Aptariamas pirminio galvos skausmo ir moterų LD komorbidiškumas bei lytinių santykių poveikis pirminiam galvos skausmui.

\section{LYTINĖS VEIKLOS SUKELTAS GALVOS SKAUSMAS}

Lytinès veiklos sukeltas galvos skausmas (LVS) - tai pirminis galvos skausmas, sukeliamas lytinès veiklos ar atsirandantis jos metu [1]. LVS anksčiau buvo vadintas gerybiniu lytinès veiklos galvos skausmu, gerybiniu kraujagysliniu lytinès veiklos skausmu, lytinių santykių sukeltu skausmu, koitaline cefalalgija, orgazmine cefalalgija ir kt. LVS paplitimas populiacijoje siekia apie 1-1,6\% [7]. Nepaisant to, spejjama, kad ligos dažnis gali būti didesnis dèl pacientu patiriamos gédos ir vengimo pasakoti apie savo lytinę veiklą [8]. Išskiriami du skausmo pasireiškimo pikai - 20-24 m. ir 35-44 metai. Vidutinis pacientų, kuriems

(C) Neurologijos seminarai, 2021. Open Access. This article is distributed under the terms of the Creative Commons Attribution 4.0 International License CC-BY 4.0 (http://creativecommons.org/licenses/by/4.0/), which permits unrestricted use, distribution, and reproduction in any medium, provided you give appropriate credit to the original author(s) and the source, provide a link to the Creative Commons license, and indicate if changes were made. 
Lentelè. Pirminio lytinès veiklos sukelto galvos skausmo kriterijai pagal trečiają Tarptautinę galvos skausmo klasifikaciją (2018 m.) [1]

A. Bent du galvos skausmo ir (ar) kaklo skausmo epizodai atitinkantys B-D kriterijus

B. Sukeliami ir atsirandantys tik lytinès veiklos metu

C. Vienas ar abu kriterijai:

1. Didejantis intensyvumas didejant lytiniam sujaudinimui

2. Staigus, sprogstantis intensyvumas prieš pat orgazmą ar jo metu

D. Stipraus skausmo trukmè nuo 1 min., iki 24 val. ir (ar) silpno skausmo trukmé - iki 72 val.

E. Nèra kitos, geriau skausmą paaiškinančios, diagnozès

Tikètina diagnozé, jei patirtas vienas skausmo epizodas.

pasireiškè pirmasis LVS epizodas, amžius siekia $35,2 \pm 10,6$ metų [8]. Vis dèlto, aprašomi pavieniai klinikiniai atvejai, kai LVS buvo nustatytas paaugliams, kuriu jauniausias - $12 \mathrm{~m}$. amžiaus $[9,10]$. LVS dažniau pasireiškia vyrams nei moterims (V:M santykis 2,9:1) [8]. Šiam galvos skausmui išsivystyti įtakos turi paveldimumas. Literatūroje minimi atvejai, kai LVS pasireiškẻ motinai ir dukteriai [7] bei keturioms seserims [11]. LVS pasižymi dideliu komorbidiškumu su kitais pirminiais galvos skausmais: $30-40 \%$ pacientų patiria fizinio krūvio sukeltą galvos skausmą, apie $35 \%$ - itampos tipo galvos skausmą, o apie $30 \%$ - migreną $[8,12]$.

LVS patofiziologija yra nežinoma. Remiantis pirmaisiais LVS aprašymais, galvos skausmas siejamas su stipriu kaklo ir apatinio žandikaulio raumenų susitraukimu bei pulso ir kraujospūdžio padidejjimu lytinès veiklos metu [13]. Vis dèlto, vèlesniais tyrimais įrodyta, kad hipertenzija nèra LVS rizikos veiksnys [8]. Anot kitų autorių, LVS gali būti susijęs su trigeminovaskulinės sistemos aktyvacija ir sutrikusia smegenų kraujotakos autoreguliacija [14]. Donnet ir kt. aprašė sąsają tarp galvos veninių ančių ir kaklo venų stenozės bei LVS [15]. 12 iš 19 LVS pacientų, atlikus galvos ir kaklo venografiją, buvo rasta skersinio ančio ir (ar) jungo venų stenozė. Šie pokyčiai kontrolinèje grupéje nebuvo aptikti.

Skausmo charakteristika. Išskiriami du LVS potipiai: preorgazminis ( 20\%) ir orgazminis ( 80\%) [7]. Preorgazminiam LVS potipiui būdingas bukas, spaudžiantis, dažniausiai abipusis skausmas pakaušyje (kitos lokalizacijos skausmas diagnozès nepaneigia), kurio intensyvumas priklauso nuo lytinio susijaudinimo, o dažnis - nuo pasiekto orgazmo dažnio. Orgazminiam LVS potipiui būdingas staigus, stiprus, sprogstantis, pulsuojantis visos galvos skausmas prieš pat orgazmą ar jo metu.

LVS trukmè tarp pacientų įvairuoja. Vidutinė stipraus skausmo trukmè - 30 minučiu (intervalas - nuo $1 \mathrm{~min}$. iki 24 val.) [8]. Didžiajai daliai pacientų stipraus skausmo trukmè neviršija 4 valandų. Jam pasibaigus, daugumai ligonių išlieka silpnas galvos skausmas, kurio vidutinẻ trukmè - 4 valandos (maksimali trukmè - 72 val.). Atnaujinus lytinę veiklą dar nepasibaigus LVS, šis linkęs sustiprèti.
Dèl šios priežasties rekomenduojama susilaikyti nuo lytinės veiklos iki galvos skausmas visiškai išnyks. Lydintys simptomai yra reti. Pacientai kartu su galvos skausmu gali jausti pykinimą (25\%) ir svaigimą (14 \%), rečiau - fotofobiją $[7,8]$.

Anot Frese ir kt. tyrimo, LVS $94 \%$ atvejų pasireiškè užsiimant lytine veikla su pastoviu partneriu, $14 \%$ - su nauju partneriu, $35 \%$ - masturbuojantis [8]. Literatūroje taip pat aprašomi pavieniai pornografijos sukelto LVS atvejai [16]. $40 \%$ pacientų galvos skausmas baigèsi nutraukus lytinę veiklą, o $51 \%$ galvos skausmas palengvėdavo pasitelkiant pasyvesnị vaidmenị lytinès veiklos metu [8]. Atkreiptinas dėmesys, kad LVS pasireiškia ne kiekvienos lytinès veiklos metu [7]. Vidutinè laikotarpio tarp skausmo epizodų trukmé siekia 3,2 $\pm 5,0$ mèn. [8]. Nepaisant to, skausmo epizodus gali skirti ilgas remisijos laikotarpis, siekiantis net iki 10 metų [17]. Diagnostika remiasi trečiosios Tarptautinès galvos skausmo klasifikacijos (angl. International classification of headache disorders, ICHD III) kriterijais (lentelè).

Diferencijuojant LVS nuo kitu būklių, derètų žinoti, kad šiam galvos skausmui nebūdinga sąmonės sutrikimas, vėmimas, regos, jutimo ar motorikos sutrikimai. Tačiau ketvirtadalis pacientų gali jausti pykinimą [8]. Taip pat literatūroje minimi pavieniai orgazmo metu pasireiškusios auros aprašymai. Minimiems pacientams išsivystė kamieninei migrenos aurai būdingi simptomai: oscilopsija, svaigimas ir dizartrija [18]. LVS epizodui pasireiškus pirmą kartą, būtina atmesti antrines galvos skausmo priežastis: subarachnoidinę hemoragiją, meningoencefalitą, intra- ar ekstrakranijinių arterijų disekaciją, grịžtamosios cerebrinės vazokonstrikcijos sindromą, smegenų venų trombozę, struktūrinius kraniocervikalinès jungties pakitimus, intrakranijinę hipotenziją, kardialinę cefalgiją, feochromocitomą, narkotinių medžiagų vartojimą [1]. Remiantis Europos galvos skausmo federacijos rekomendacijomis, pacientams, patyrusiems LVS, rekomenduojama atlikti smegenų magnetinio rezonanso tyrimą (MRT) su angiografijos ir venografijos režimais, miego ir slankstelinių arterijų ultragarsinị ar kompiuterinès tomografijos / MRT angiografijos tyrimą, siekiant atmesti gyvybei pavojingas būkles [19]. Gydytojo nuožiūra papildomai gali būti atliekama juosmens punkcija, eritrocitų nusėdimo greičio, $\mathrm{C}$ reaktyviojo baltymo ir D-dimeruc koncentracijos kraujyje tyrimai.

Gydymas. Nustačius LVS diagnozę, ligonio edukacija turi didelę reikšmę. Pirmiausia, pacientą reikètų įtikinti, kad LVS yra nepavojingas, praeinantis, o simptomai gali būti malšinami vaistais, užimant pasyvesnị vaidmenị lytinės veiklos metu ar aktą nutraukiant [12]. Priepuoliams gydyti gali būti skiriami ị nosị purškiami triptanai, kurių efektyvumas, anot Evers ir kt., siekia apie $50 \%$ [20]. LVS trumpalaikei prevencijai vartojamas indometacinas (25-225 mg per dieną ar 25-100 mg 30-60 min. prieš numatomą lytinę veiklą), sumatriptanas (30-60 min. prieš numatomą lytinę veiklą) ar ilgalaikei prevencijai - propranololis (40-240 mg per dieną, 3-6 mènesius) [7, 12, 21]. 


\section{PIRMINIS GALVOS SKAUSMAS IR MOTERU LYTINE DISFUNKCIJA}

Dèl daugumos pacientų patiriamos gèdos ir vengimo spontaniškai išsakyti skundus, susijusius su LD, konsultacijos metu rekomenduojama aktyviai paklausti apie sergančiujuc pirminiu galvos skausmu lytinę funkciją. Nepatyrusiam gydytojui gali būti sunku ir net gèdinga rasti būdą užduoti subtilius klausimus apie seksualinę sveikatą. Todèl tam gali pasitarnauti LD vertinantys klausimynai, pavyzdžiui, trumpasis moters lytinės funkcijos klausimynas, kurị sudaro vos 6 klausimai [6].

\section{LYTINIŲ SANTYKIU巳 POVEIKIS PIRMINIAM GALVOS SKAUSMUI}

Remiantis Abdollahi ir kt. tyrimu, kuriuo siekta išsiaiškinti moterų, sergančių migrena, LD paplitimą Irane, nustatyta, kad LD dažnis siekia 68,4 \% [22]. Moterys, kurioms buvo nustatyta LD, statistiškai reikšmingai dažniau patyrè galvos skausmą, nei lytinės funkcijos sutrikimų neturinčios moterys (atitinkamai 7,9 d/mèn. ir 3,5 d/mėn.). Kitame tyrime, atliktame Izraelyje, buvo analizuotas migrenos poveikis lytiniam gyvenimui. Nustatyta, kad migrena sergančios pacientės dažniau patiria lytinių santykių baimę, skausmą santykių metu ir mažesnị pasitenkinimą, nei migrena nesergančios moterys [2]. Panašių rezultatų gauta Nappi ir kt. tyrime, kad pirminio galvos skausmo (migrenos, su ar be auros bei itampos tipo ar abiejų tipų galvos skausmų) diagnozė stipriai koreliuoja su lytinių santykių metu patiriamu didesniu skausmu [23]. Šią asociaciją galima paaiškinti centrine skausmo takų sensitizacija sergant migrena. Klinikiniai ir eksperimentiniai tyrimai rodo, kad migrenos metu padidėjęs nociceptinių trišakio nervo neuronų jaudrumas aktyvuoja nusileidžiančius skausmą perduodančius takus ir mažina skausmo perdavimą slopinančių takų veikimą [24]. Kitas galimas mechanizmas - didelis galvos skausmą patiriančių pacientų demesys savo skausmui ir somatiniams simptomams. Priepuolinis skausmas yra susijęs su skausmo pasikartojimo baime ir veiklų, suvokiamų kaip sukeliančių skausmą, vengimu [2]. Nappi ir kt. taip pat nustatè, kad pacientès, sergančios lètiniu itampos tipo galvos skausmu, dažniau patiria LD, o LD ir įtampos tipo galvos skausmo komorbidiškumas koreliuoja su didesniu depresijos dažniu [23]. Analogiškas išvadas pateikia Aydın ir kt. tyrimas: migrena bei ịtampos tipo galvos skausmas sukelia LD ir pablogina moterų gyvenimo kokybę [4]. Tyrime rasta, kad tiek migrena, tiek įtampos tipo galvos skausmas buvo reikšmingai susiję su visų lytinès funkcijos sričių mažesniais įverčiais. Remiantis Schumacher ir kt. tyrimo išvadomis, migreninio galvos skausmo retinimas ir gretutinių ligų gydymas turi teigiamą poveiki lytinei funkcijai ir pasitenkinimui [25].

Nors pirminis galvos skausmas yra susijęs su LD, daliai pacientu lytiniai santykiai gali palengvinti galvos skausmą. Literatūroje aprašomi pavieniai klinikiniai atve- jai, kai orgazmas visiškai nutraukdavo klasterinị galvos skausmą [5, 26]. Manoma, kad vienas iš galimų skausmo slopinimo mechanizmų - orgazmo sukeliama pagumburio nervinių tinklų moduliacija. Šią hipotezę patvirtina pozitronų emisijos tomografijos (PET) tyrimuose fiksuojama užpakalinès pagumburio dalies aktyvacija, kuri stebima tiek klasterinio galvos skausmo, tiek orgazmo metu [26, 27].

Taip pat tirtas lytinių santykių poveikis migrenai. Anot Hambach ir kt., tik trečdalis tyrime dalyvavusių respondentų nurodè, kad skausmo metu yra turèję pavienių lytinių santykių (nuo 2 iki 10 kartų migrenos ir nuo 1 iki 5 kartų klasterinio galvos skausmo priepuolių metu). 63,9\% pacientų, kurie užsièmė lytine veikla migrenos priepuolio metu, skausmas sumažėjo [5]. Iš jų 70,9 \% patyrẻ vidutinị skausmo sumažejjimą ar visišką jo išnykimą. Tik 33,0 \% klasterinio galvos skausmo pacientų nurodè, kad lytinė veikla sumažino galvos skausmą, tačiau iš ju net 90,9 \% patyrè vidutinị ar visišką skausmo sumažèjimą. Galvos skausmo pokyčiai nepriklausè nuo lytinès veiklos rūšies, partnerio, pozos ir trukmès nuo galvos skausmo pradžios. Lytinè veikla dažniau sumažindavo migrenos sukeltą galvos skausmą vyrams nei moterims (atitinkamai 73,3\% ir $58,0 \%)$. Nepaisant minètų rezultatų, $34 \%$ migrenos ir $50 \%$ klasterinio galvos skausmo pacientų lytinè veikla skausmą sustiprindavo [5].

\section{IŠVADOS}

- LVS diagnostika, remiantis ICHD III kriterijais, yra nesudètinga, tačiau, LVS pasireiškus pirmą kartą, privaloma paneigti pavojingas antrines galvos skausmo priežastis. LVS gali lydèti pykinimas, tačiau esant vėmimui, regos, jutimo ar motorikos sutrikimams vertètų apgalvoti alternatyvias priežastis. Pagrindiniai rekomenduojami tyrimai: galvos smegenų KT ar MRT su angiografija, miego ir slankstelinių arterijų ultragarsinis tyrimas.

- Tiek lytinès veiklos sukelto galvos skausmo, tiek ir pirminio galvos skausmo sukeltos lytinès disfunkcijos diagnostika yra nepakankama, todèl gydytojui rekomenduojama aktyviai klausti apie galimus sutrikimus.

- Svarbu nepamiršti, kad, pavykus sumažinti migrenos ar kito pirminio galvos skausmo naštą, galima tikètis moterų lytinès funkcijos pagerẻjimo.

- Didžioji dalis pacientų migrenos ar klasterinio galvos skausmo priepuolio metu dėl stipraus skausmo ir lydinčių reiškinių lytinių santykių neturi, todèl dalies migrena sergančių ligonių nurodomas skausmo sumažėjimas lytinių santykių metu yra nepakankamas, kad būtų galima rekomenduoti tokị migrenos priepuolio nutraukimo būdą.

\section{Literatūra}

1. Headache Classification Committee of the International Headache Society. The International Classification of Headache Disorders, 3rd edition. Cephalalgia 2018; 38: 1-211. 
2. Ifergane G, Ben-Zion IZ, Plakht Y, et al. Not only headache: higher degree of sexual pain symptoms among migraine sufferers. J Headache Pain 2008; 9: 113-7. https://doi.org/ 10.1007/s10194-008-0028-8

3. Ege E, Akın B, Yaralı Arslan S BN. Prevalence and risk factors of sexual dysfunction among healthy women. TUBAV Bilim 2010; 3: 137-44.

4. Aydın M, Bitkin A, İrk1lata L, et al. The effect of migraine and tension-type headaches on female sexual functions: a prospective, cross-sectional, controlled study. Turk J Urol 2018; 44(5): 418-22. https://doi.org/10.5152/tud.2018.45228

5. Hambach A, Evers S, Summ O, et al. The impact of sexual activity on idiopathic headaches: an observational study. Cephalalgia 2013; 33: 384-9. https://doi.org/10.1177/ 0333102413476374

6. Isidori AM, Pozza C, Esposito K, et al. Development and validation of a 6-item version of the female sexual function index (FSFI) as a diagnostic tool for female sexual dysfunction. J Sex Med 2010; 7: 1139-46. https://doi.org/10.1111/j.17436109.2009.01635.x

7. Bahra A. Other primary headaches - thunderclap-, cough-, exertional-, and sexual headache. J Neurol 2020; 267: 1554-66. https://doi.org/10.1007/s00415-020-09728-0

8. Frese A, Eikermann A, Frese K, et al. Headache associated with sexual activity: demography, clinical features, and comorbidity. Neurology 2003; 61: 796-800. https://doi.org/ 10.1212/01.WNL.0000083988.98336.A3

9. Evers S, Peikert A, Frese A. Sexual headache in young adolescence. Headache 2009; 49: 1234-5. https://doi.org/ 10.1111/j.1526-4610.2009.01498.x

10. Gelfand AA, Goadsby PJ. Primary sex headache in adolescents. Pediatrics 2012; 130: e439-41.

11. Johns DR. Benign sexual headache within a family. Arch Neurol 1986; 43: 1158-60. https://doi.org/10.1001/ archneur.1986.00520110048013

12. Starling AJ. Unusual headache disorders. Contin Lifelong Learn Neurol 2018; 24: 1192-208. https://doi.org/10.1212/ CON.0000000000000636

13. Lance JW. Headaches related to sexual activity. J Neurol Neurosurg Psychiatry 1976; 39: 1226-30. https://doi.org/ 10.1136/jnnp.39.12.1226

14. Anand KS, Dhikav V. Primary headache associated with sexual activity. Singapore Med J 2009; 50: e176-7.

15. Donnet A, Valade D, Houdart E, et al. Primary cough headache, primary exertional headache, and primary headache associated with sexual activity: a clinical and radiological study. Neuroradiology 2013; 55: 297-305. https://doi.org/ 10.1007/s00234-012-1110-0

16. Chen WH, Chen KY, Yin HL. Pornography headache. Clin Neurol Neurosurg 2018; 164: 11-3. https://doi.org/10.1016/ j.clineuro.2017.10.026

17. Østergaard JR, Kraft M. Benign coital headache. Cephalalgia 1992; 12: 353-5. https://doi.org/10.1111/j.1468-2982. 1992.00353.x

18. Angus-Leppan H, Caulfield A. Orgasmic migraine aura: report of two cases. Cephalalgia 2019; 39: 153-6. https://doi.org/10.1177/0333102418771373
19. Mitsikostas DD, Ashina M, Craven A, et al. European Headache Federation consensus on technical investigation for primary headache disorders. J Headache Pain 2015; 17: 1-8. https://doi.org/10.1186/s10194-016-0596-y

20. Frese A, Gantenbein A, Marziniak M, et al. Triptans in orgasmic headache. Cephalalgia 2006; 26: 1458-61. https://doi.org/10.1111/j.1468-2982.2006.01224.x

21. Frese A, Rahmann A, Gregor N, et al. Headache associated with sexual activity: prognosis and treatment options. Cephalalgia 2007; 27: 1265-70. https://doi.org/10.1111/ j.1468-2982.2007.01449.x

22. Abdollahi M, Toghae M, Raisi F, et al. The prevalence of female sexual dysfunction among migraine patients. Iran $\mathrm{J}$ Neurol 2015; 14: 8-11.

23. Nappi RE, Terreno E, Tassorelli C, et al. Sexual function and distress in women treated for primary headaches in a tertiary university center. J Sex Med 2012; 9: 761-9. https://doi.org/ 10.1111/j.1743-6109.2011.02601.x

24. Welch KMA. Contemporary concepts of migraine pathogenesis. Neurology 2003; 61: S2-8.

25. Schumacher L, Wing R, Thomas JG, et al. Does sexual functioning improve with migraine improvements and/or weight loss? A post hoc analysis in the women's health and migraine (WHAM) trial. Obes Sci Pract 2020; 6: 596-604. https://doi.org/10.1002/osp4.443

26. Gotkine M, Steiner I, Biran I. Now dear, I have a headache! Immediate improvement of cluster headaches after sexual activity. J Neurol Neurosurg Psychiatry 2006; 77: 1296. https://doi.org/10.1136/jnnp.2006.092643

27. May A, Bahra A, Büchel C, et al. Hypothalamic activation in cluster headache attacks. Lancet $1998 ; 352: 275-8$. https://doi.org/10.1016/S0140-6736(98)02470-2

\section{Jokubaitis, K. Ryliškienė}

\section{HEADACHE ASSOCIATED WITH SEXUAL ACTIVITY}

\section{Summary}

Headache associated with sexual activity (HSA) is a type of primary headache disorder that is precipitated by sexual activity. The reported prevalence of HSA is about 1-1.6\%. Nonetheless, it is possible that the incidence of the disease may be much higher due to patient's unwillingness to express sexual activity-related complaints. HSA is linked to a high rate of other primary headache disorders. Treatment of HSA consists of acute pain management and headache recurrence prevention. This article reviews the epidemiology, pain characteristics, diagnostic criteria, differential diagnosis, and treatment of HAS. The impact of sexual activity on acute attacks of primary headache disorders and the comorbidity of primary headache and sexual dysfunction are also discussed.

Keywords: primary headache associated with sexual activity, pain characteristics, diagnosis, treatment, sexual dysfunction.

Gauta:

20210419
Priimta spaudai: 20210511 